\title{
Communication Skills
}

National Cancer Institute

\section{Source}

National Cancer Institute. Communication Skills. NCI Thesaurus. Code C121189.

An assessment of the Adaptive Behavior Assessment System, Second Edition where communication skills such as speech, language, listening, and conversation are evaluated. 